\title{
Mesmas instituições, mesmos resultados? Comparando o efeito da competição eleitoral sobre os níveis de concentração de votos $^{1}$
}

Glauco Peres da Silva

\section{Introdução}

Nas pesquisas sobre sistemas eleitorais, a magnitude dos distritos é utilizada como variável explicativa de muitos fenômenos, como competição partidária (Blais e Lago, 2009), número de partidos (Ferree, Powell e Scheiner, 2014) e representação (Stadelmann, Portmann e Eichenberger, 2014), sendo o voto pessoal (André e Depauw, 2013) um caso particular desse tipo de relação. O vínculo entre magnitude e voto pessoal está no fato de que o número de cadeiras em disputa em um distrito é uma proxy para o nível de competição entre os candidatos, por vezes dentro da mesma legenda. Ao mesmo tempo, essa competição eleitoral traz incentivos variados para que os candidatos enalteçam traços pessoais para sua sobrevivência política (Carroll e Eichorst, 2013) a depender das regras eleitorais (Carey e Shugart, 1995). Sistemas proporcionais de lista aberta, como no Brasil, apresentariam níveis elevados de disputa intrapartidária em uma eleição e, combinados com distritos de elevada magnitude existentes no país, acentuariam marcadamente o incentivo ao voto pessoal. Por outro lado, existe a argumentação de que o voto pessoal estimula a concentração de votos, já que esse tipo de relação com o eleitorado teria uma localidade específica como referência (Crisp et al., 2013). Essas constatações fecham um ciclo relacional entre competição eleitoral, personalismo e concentração de votos, que organizam as pesquisas sobre estudos eleitorais.

Essa mesma estrutura de argumentação é adotada por trabalhos que lidavam com os incentivos do sistema eleitoral no Brasil, pois o voto pessoal levaria à concentração ${ }^{2}$ espacial de votos (p. ex., Ames, 2001), ao menos para políticos que não encontrassem um segmento particular da população com o qual pudessem estabelecer vínculo. O comum seria identificar o vínculo regionalizado. Uma vez eleito, o deputado retribuiria os votos recebidos através do direcionamento de emendas orçamentárias para a região estabelecida ou, de forma mais geral, praticando constituency service. Atuaria especificamente para uma parcela da população conhecida, esperando, dessa forma, continuar a receber os

\footnotetext{
1 Uma versão anterior deste artigo foi apresentada no $39^{\circ}$ Encontro da Anpocs em Caxambu. Agradeço aos participantes pelos comentários e sugestões. Valem as observações de praxe quanto à responsabilidade autoral do texto apresentado aqui.

2 "Concentração regional", "espacial", "territorial" ou apenas "concentração" serão utilizadas indistintamente ao longo deste artigo e se referem à distribuição territorial de votos de determinado candidato.
} 
votos desses eleitores. Ou seja, as regras eleitorais afetariam tanto a eleição em si, ao induzir determinado tipo de campanha, quanto o comportamento parlamentar.

Assim, em um momento, essas regras incentivariam o voto pessoal, que se associa à regionalização do voto (p. ex., Crisp e Ingall, 2002); em outro momento, essas mesmas regras fomentariam a criação de relações personalistas ao longo do mandato, localistas em essência, compreensão esta que se conforma também com o tipo de representação política que muitos entendem ser a regra no Brasil (Hagopian, 2007). Haveria, assim, uma dupla força agindo para a observação da regionalização dos votos para a Câmara de Deputados no Brasil.

Essa interpretação comum sobre o Brasil tem seu suporte teórico disputado em período mais recente no que se refere especificamente à atuação parlamentar, na medida em que se questiona a importância das emendas, a exemplo da pork barrel politics, como aspecto relevante para a reeleição (Pereira e Rennó, 2007; Lago e Rotta, 2014). Críticas nesse sentido também surgem de outros trabalhos, que apontam para a mudança no comportamento dos deputados no que tange à utilização de emendas orçamentárias para atender a demandas locais (Mesquita et al., 2014), como também indicam a baixa efetividade em termos de retorno eleitoral (Baião, 2016). De outra parte, referindo-se particularmente ao impacto que a regra eleitoral tem sobre o comportamento de um parlamentar, Carvalho (2003) demonstra ser a dominância local o incentivador da atividade localizada e não a concentração de votos. Mais relevante aos propósitos deste artigo, no que se refere ao momento eleitoral, verifica-se que os níveis de concentração de votos dos candidatos a deputado federal não são elevados no nível municipal como a literatura fazia crer. Avelino, Biderman e Silva $(2011,2016)$ encontram valores muito menores do que se esperaria de acordo com a interpretação tradicional. Seus resultados sugerem que se há algum nível geográfico em que a concentração de votos ocorre, este se dá em um patamar geográfico mais amplo, como as microrregiões do IBGE. Então, resta ainda verificar empiricamente se os incentivos eleitorais de fato interferem na espacialização dos votos.

Em suma, observa-se que a competição em uma eleição, avaliada pela magnitude dos distritos, afeta a distribuição regional observada de votos. Nesse debate, o caso brasileiro cria um ambiente favorável a avaliações empíricas, pois as disputas para os cargos de deputado estadual e federal ocorrem simultaneamente, no mesmo distrito eleitoral, porém com magnitudes distintas. Como as demais regras eleitorais são as mesmas, seguindo a interpretação do impacto dos incentivos provenientes das regras eleitorais sobre o comportamento dos candidatos, supõe-se que os candidatos ao cargo de deputado estadual atuem de maneira semelhante aos concorrentes ao cargo de deputado federal, e que, nesse sentido, buscariam a consolidação de seus votos em áreas geográficas bastante específicas como previsto pela teoria. Se a ênfase a características pessoais no momento da eleição está relacionada ao nível de competição eleitoral e, por outro lado, influencia a concentração de votos, essa lógica se aplica às disputas tanto para 
o legislativo federal no Brasil quanto para o estadual. Ou seja, aquilo que se afirma serem incentivos institucionais para determinado comportamento de um candidato a deputado federal decorrentes da legislação na disputa eleitoral também seria válido para os candidatos a deputado estadual.

Mais interessante, essa diferença nas magnitudes dos distritos permite que se teste a sua importância em um ambiente institucional formal que, de resto, é idêntico. Nesse sentido, a comparação dos níveis de concentração de votos entre os candidatos a deputado estadual e federal contribui para que se compreenda o impacto de um relevante aspecto da regra eleitoral: variações da magnitude influenciam a dispersão de votos ao longo do território? Como um mesmo indivíduo compete para cargos diferentes em diferentes eleições, pode se aproveitar dessa alternativa na forma de um quase experimento, já que o indivíduo se autosseleciona em relação à cadeira que disputará, tornando possível controlar por características pessoais que podem influenciar a dispersão de seus votos. E, de fato, os resultados encontrados aqui sugerem que a magnitude afeta a concentração de votos no sentido teoricamente esperado: quanto maior a magnitude do distrito, mais concentrados espacialmente estão os votos. Deve-se destacar ainda um resultado interessante encontrado, mas que ainda carece de explicação teórica: candidatos que concorrem ao mesmo cargo em eleições consecutivas dispersam seus votos pelo território. A contribuição deste artigo, portanto, é empírica por encontrar meios de mensurar uma relação teoricamente esperada, possibilitando avanços posteriores nas consequências teóricas de tal relação. A fim de apresentar essa discussão, este artigo, na próxima seção, introduz o problema investigado para, em seguida, apresentar o desenho de pesquisa, analisar os dados e encerrar com uma discussão geral a respeito da importância de seus achados.

\section{Apresentação do problema}

Para a literatura que se volta a estudos eleitorais, a magnitude dos distritos importa. Desde trabalhos clássicos de Duverger (1959), Rae (1972) e Downs (1957), o número de cadeiras em disputa é um aspecto fundamental do sistema eleitoral para a compreensão do conjunto de incentivos diante dos atores políticos. Afinal, a magnitude indica a quantidade de prêmios em disputa em uma eleição e tem, assim, consequências sobre a atuação e a estruturação do sistema partidário de um país. Essa longa tradição de avaliação dos sistemas eleitorais se dividiu em segmentos relacionando a importância da magnitude dos distritos eleitorais a outros aspectos das eleições. Essa variável se tornou indicador de várias dimensões das eleições, como a competição eleitoral, por exemplo. Desde Carey e Shugart (1995), tem-se a visão básica de que, em sistemas de lista aberta, a competição eleitoral eleva a importância do voto pessoal. Esse efeito da expansão do nível de disputa geral ocorre em razão do aumento da competição intrapartidária. Sendo proxy desse aspecto, a magnitude seria assim um indicativo do nível de concorrência 
dentro de uma mesma lista. Nessa situação, em um pleito, os candidatos precisam se diferenciar de seus colegas de legenda, o que significa criar uma imagem pessoal junto ao eleitorado. André e Depauw (2013) argumentam que ainda se mantém a hipótese de que a competição intrapartidária molda os incentivos para o cultivo de uma reputação pessoal e, consequentemente, permanece o incentivo no momento pós-eleitoral para se envolver em qualquer ação voltada para o seu eleitorado (constituency), no qual a sua reputação se baseia. Ou seja, a magnitude indica o estímulo para que os indivíduos realcem suas características individuais junto aos eleitores, tanto durante a eleição quanto ao longo do mandato. Complementando a ideia, Golden e Min (2013) também sustentam que nos lugares onde os políticos praticam a pork barrel politics, suas ações se voltam para constituencies específicas a fim de elevar a sua visibilidade entre os eleitores e assim aumentar as suas chances de reeleição. Porém reforçam que essa ideia é de difícil teste empírico, já que há muitas divergências na classificação das alocações de políticas feitas como pork/patronagem ou programáticas. Apesar dessa dificuldade, está mantida a disposição para a ação voltada a parcelas específicas do eleitorado. Na mesma linha, Nielson (2002, apud Primo e Snyder Jr., 2008) destaca essa dinâmica no momento eleitoral ao colocar sua posição desta forma:

This brings us to policymakers' incentives, which political institutions shape.

The personal vote, where politicians pursue votes based on their individual popularity that they heighten through promises of pork and patronage, makes politicians beholden to narrow constituencies and relatively indifferent to national policy goals. The personal vote thus undermines public-goods productions (ênfase minha).

Assim, a magnitude de um distrito seria o indicativo tanto de um determinado comportamento no momento eleitoral quanto de um comportamento parlamentar indesejado em que há dificuldade de se observar diretamente, mas que é ampla e teoricamente esperado pelos trabalhos que lidam com o tema.

De outra parte, é identificada a existência de relação entre o voto pessoal e a concentração de votos (Crisp e Ingall, 2002, Crisp et al., 2013). A concepção básica é a de que as constituencies, por serem particulares, tendem a estar espacialmente delimitadas. Se refeririam comumente a uma localidade regionalmente demarcada. A campanha se direcionaria para essa região. Deve-se considerar, porém, que esse incentivo seria mediado por diferentes outros fatores que atuam em uma determinada eleição, mas o estímulo do voto pessoal se focaria em áreas delimitadas do território e estaria posto uma vez que o incentivo ao voto pessoal exista. Essa constatação completa a relação entre competição eleitoral, personalismo e concentração de votos. Por exemplo, Crisp e Ingall (2002) e Crisp et al. (2013) argumentam que, em sistemas nos quais os eleitores podem atribuir votos a candidatos individuais, estes são incentivados a construir nichos de apoio dentro dos distritos. Também Nemoto e Shugart (2013), lidando com o caso japonês, 
mostram que o sistema proporcional de lista aberta cria incentivos para que os candidatos concentrem seus esforços regionalmente durante a campanha. Swindle (2002), por sua vez, busca encontrar uma relação causal inversa entre voto pessoal e concentração de votos: candidatos com votação mais concentrada atuariam no sentido de criar uma reputação pessoal local ao longo de seu mandato. Porém, não nega que haja o incentivo para a concentração durante as eleições. Essa elaboração teórica é válida para todos os sistemas eleitorais que possuam determinado conjunto de regras eleitorais, cujo incentivo em termos comparados será mais ou menos percebido empiricamente de acordo com os outros incentivos existentes em uma disputa eleitoral.

Essas justificativas para o foco da ação dos deputados direcionados para uma constituency em particular culminou no Brasil com a formação dos redutos eleitorais informais ou a manutenção dos redutos eleitorais ou grotões. Fecha-se um ciclo: os incentivos eleitorais refletem-se também no comportamento parlamentar. Por essa razão, há uma dupla dimensão nessas análises sobre o Brasil. De um lado, voltam-se para identificar os níveis de dominância local e de concentração eleitoral focadas na formação de constituency. Essa identificação seria a evidência da associação entre a arena eleitoral e a legislativa. Vários estudos se debruçaram sobre a avaliação dessa relação. Por exemplo, ainda que Ames (1995a, 1995b, 2001) admita a possibilidade de que o foco de atuação do parlamentar se volte a um segmento do eleitorado que não está necessariamente concentrado em determinadas áreas específicas, como professores ou policiais, todas as suas avaliações empíricas lidam apenas com regionalização do voto, quando cria a tipologia "concentrado/disperso". A estruturação empírica de outras pesquisas, como, por exemplo, Pereira e Rennó $(2001,2007)$, se volta a observar a concentração de votos nos municípios como fenômenos decorrentes das regras eleitorais para justificar a atuação do parlamentar. Nesse sentido, Carvalho (2003) aponta que a atuação do deputado voltada para a manutenção de suas constituencies é a dominância e não a concentração. De outro lado, há trabalhos que contestam o uso de emendas orçamentárias para atender a demandas locais (Mesquita et al., 2014), enquanto outros indicam a baixíssima efetividade em termos de votos obtidos com essa prática (Baião, 2016). Na mesma direção, trabalhos como o de Pereira e Rennó (2007) e de Lago e Rotta (2014) não encontram evidências para que o uso das emendas ao orçamento federal seja condição suficiente para a reeleição dos deputados federais. Inclusive, Martin (2011) apresenta evidências de que o sistema eleitoral não é suficiente para explicar o comportamento dos legisladores ao longo do mandato, o que implicaria introduzir novos elementos explicativos para além do sistema eleitoral no sentido de avaliar essa reação dos políticos. A capacidade das regras das eleições em afetar o comportamento parlamentar não reflete a variedade de casos observados.

Porém, vale dizer que essa associação entre voto pessoal e concentração de votos referente ao momento da eleição não é particular ao caso brasileiro. Ainda que haja eventual desacordo sobre o impacto dessa regra sobre o comportamento dos legisladores 
no Brasil, o sistema eleitoral continua a criar incentivos específicos para o comportamento de eleitores e candidatos durante as eleições. Esses estímulos são baseados no nível de competição eleitoral, no cultivo do voto pessoal e na concentração espacial do voto. Inclusive, o Brasil se encaixaria nessa abordagem mais ampla como um caso extremo, já que os incentivos do sistema eleitoral do país estão entre os maiores promotores do personalismo, dada a magnitude bastante elevada dos distritos eleitorais. Nesse sentido, no que se refere ao momento da eleição, há um argumento teórico com a seguinte estrutura lógica nas pesquisas empíricas que avaliam sistemas eleitorais tais como o brasileiro: maior competição - maior influência do voto pessoal - maior concentração de votos. Diante dessa relação teoricamente construída, este artigo busca averiguar se a mudança de magnitude, proxy para a competição eleitoral, afeta os níveis de concentração espacial de votos dos candidatos ao legislativo, tomando o Brasil como caso a ser avaliado.

Ainda de forma geral, a dificuldade da literatura que trata do Brasil se volta às evidências empíricas da relação entre voto pessoal, competição eleitoral e concentração de votos. Como apresentado em Avelino, Biderman e Silva (2011), as medidas comumente utilizadas para concentração de votos não dão conta da avaliação do nível de dispersão de votos dos candidatos aos cargos legislativos. Para contornar o problema, esses autores adaptam um índice utilizado na economia regional, o índice G, e o aplicam para São Paulo. Seus resultados sugerem que a concentração, quando há, se dá em níveis geográficos maiores do que o municipal, como as microrregiões do IBGE, o que contraria as outras abordagens empíricas. Em outro texto, Avelino, Biderman e Silva (2016) aplicam a mesma metodologia para o restante do país e encontram que em São Paulo o nível de concentração é ainda mais elevado do que nos demais estados. Esse resultado reforça a ideia de que a magnitude elevada em São Paulo faz com que os candidatos concentrem mais seus votos. Novamente, tal achado contraria a relação teórica estabelecida, mas ainda mantém aberta a questão da relação entre a regra eleitoral, particularmente a competição eleitoral em termos de magnitude distrital, e a dispersão de votos dos candidatos.

Entretanto, o caso brasileiro é particularmente interessante para a avaliação empírica dos efeitos das regras eleitorais. Apesar de as disputas para os cargos legislativos estaduais e federal se darem sobre as mesmas regras - são escolhidos pela população em eleições proporcionais que ocorrem em distritos que são os estados da federação através de listas abertas -, há uma grande diferença quanto ao número de cadeiras em disputa: o número de deputados estaduais a serem eleitos é bastante superior ao número de deputados federais ${ }^{3}$. A Tabela 1 mostra esses números por estado ${ }^{4}$ :

\footnotetext{
3 Para estados com número menor ou igual a 12 deputados federais, o número de deputados estaduais é três vezes o número de deputados federais. Já se o número de deputados federais é superior a 12 , o número de deputados estaduais é igual a 36 mais a diferença entre o número de deputados federais e 12. Assim, um estado com 22 deputados federais, caso do Ceará, terá $36+(22-12)=46$ deputados estaduais.

${ }^{4}$ Apesar de presente na Tabela 1, o Distrito Federal não foi considerado na análise empírica por seu diferente padrão de regionalização, em que não há municípios que o conformem.
} 
Tabela 1

Número de cadeiras em disputa por estado para os cargos legislativos estadual e federal

\begin{tabular}{|c|c|c|}
\hline $\begin{array}{l}\text { Unidades da } \\
\text { federação }\end{array}$ & $\begin{array}{l}\text { Número de } \\
\text { deputados } \\
\text { estaduais }\end{array}$ & $\begin{array}{c}\text { Número de } \\
\text { deputados } \\
\text { federais }\end{array}$ \\
\hline$A C$ & 24 & 8 \\
\hline $\mathrm{AL}$ & 27 & 9 \\
\hline AM & 24 & 8 \\
\hline$A P$ & 24 & 8 \\
\hline BA & 63 & 39 \\
\hline $\mathrm{CE}$ & 46 & 22 \\
\hline DF & 24 & 8 \\
\hline ES & 30 & 10 \\
\hline GO & 41 & 17 \\
\hline MA & 42 & 18 \\
\hline MG & 77 & 53 \\
\hline MS & 24 & 8 \\
\hline MT & 24 & 8 \\
\hline PA & 41 & 17 \\
\hline PB & 36 & 12 \\
\hline PE & 49 & 25 \\
\hline PI & 30 & 10 \\
\hline PR & 54 & 30 \\
\hline RJ & 70 & 46 \\
\hline RN & 24 & 8 \\
\hline RO & 24 & 8 \\
\hline RR & 24 & 8 \\
\hline RS & 55 & 31 \\
\hline SC & 40 & 16 \\
\hline SE & 24 & 8 \\
\hline SP & 94 & 70 \\
\hline TO & 24 & 8 \\
\hline Total & 1.059 & 513 \\
\hline
\end{tabular}

Fonte: <www.camara.gov.br>.

Essa variação possibilita a exploração do efeito da mudança de magnitude dentro de um mesmo estado. A alteração de magnitude intradistrito eleitoral cria uma oportunidade substantiva para o controle de efeitos não observáveis, o que será explorado adiante. Ademais, os números de candidatos por eleição também variam de acordo com o cargo em disputa. O número de candidatos ao cargo de deputado estadual é bastante superior ao dos que disputam o cargo de deputado federal: a média nacional de candidatos a deputado estadual por distrito é de 440, contra 170 para deputado federal. Esse número tem impacto teórico sobre o nível de competição e, consequentemente, sobre a necessidade de formação de uma reputação pessoal, por um lado, e afeta os custos de campanha, por outro. Com maior número de candidatos, a reputação pessoal se torna ainda mais necessária. Há um número maior de pessoas das quais é preciso se diferenciar. Por essa razão, a concentração de votos nesses casos tenderia a ser maior. O político conseguiria tornar-se conhecido de um número menor de eleitores, o que o forçaria a 
privilegiar ainda mais a concentração de seus votos. Porém, com relação aos custos de campanha, as disputas para deputado federal costumam demandar mais gastos. Os candidatos precisam alcançar um número maior de votos para serem eleitos, já que a disputa é por número menor de cadeiras em relação ao cargo de deputado estadual. Portanto, é preciso se fazer conhecer por uma parcela maior do eleitorado, o que levaria à dispersão de seus votos finais. Por outro lado, se há maior número de candidatos, os custos também sobem, em razão de a disputa se tornar mais acirrada, o que mais uma vez dificulta a dispersão. Assim, apesar de as regras eleitorais serem as mesmas, o que provocaria o mesmo conjunto de estímulos entre os candidatos para ambas as disputas, as variações apresentadas alteram os incentivos colocados para os candidatos e consequentemente os resultados esperados para os níveis de concentração de votos em cada uma das eleições.

Apesar disso, a mera comparação direta entre indicadores de concentração para diferentes distritos não é um procedimento adequado, pois supõe que os candidatos em diferentes distritos sejam em média semelhantes em suas características individuais e também que as características distritais, como a distribuição da população pelo território, fator que afeta a dispersão dos votos, também sejam semelhantes. Em um país como o Brasil, essa é uma hipótese bastante forte. Do ponto de vista metodológico, porém, o caso brasileiro é vantajoso na medida em que as disputas para os legislativos estaduais seguem a mesma regra do legislativo federal, com a única diferença sendo a magnitude dos distritos eleitorais. As comparações possíveis entre os dois níveis de concorrência criam uma alternativa, já que os fatores de ambiente que não são observados, mas que afetariam um dos níveis de disputa, seriam em boa medida os mesmos que afetariam o outro nível. Nesse sentido, tem-se um caso interessante de quase experimento para efeito da avaliação das diferentes magnitudes sobre a concentração espacial de votos.

\section{Desenho de pesquisa}

O quase experimento se constrói pela consideração do posto ao qual um determinado indivíduo decide concorrer. Supõe-se aqui que indivíduos mais competitivos buscarão disputar o cargo de deputado federal, enquanto os menos competitivos buscarão competir para o cargo de deputado estadual. Como a magnitude dos distritos para esse cargo é maior, é preciso isolar os efeitos da competitividade dos indivíduos para a avaliação da magnitude sobre a competição. O procedimento para essa separação é a consideração das escolhas dos indivíduos sobre qual cargo concorrer e o resultado eleitoral obtido, como uma medida de competitividade do indivíduo. Ao longo de sua carreira, o indivíduo pode alternar os cargos pelos quais concorre. No problema tratado aqui, interessa-nos os indivíduos que concorrem alternadamente para os cargos de deputado federal ou estadual em eleições consecutivas. Aqueles que sistematicamente se mantêm concorrendo para um ou outro cargo avaliam suas chances de determinada forma e os resultados eleitorais são 
interpretados dentro dessa percepção. Mas, para um outro conjunto de políticos que alternam as suas escolhas entre a disputa para os cargos de deputado estadual e federal, pode-se dizer que essa sua alternativa é circunstancial e em certa medida depende de diversos fatores não observáveis. Por essa razão, a avaliação dos efeitos da magnitude se dará pela consideração dos indivíduos que concorrem em dois pleitos consecutivos, comparando seus resultados observados pela alternância de disputa entre um cargo e outro. Dessa forma, torna-se possível identificar os efeitos das regras sobre o nível de concentração de votos individuais, quando o político altera o cargo pelo qual concorre.

A concentração de votos será mensurada pelo índice $G$ (Avelino, Biderman e Silva, 2011 , 2016). Esse indicador traz a vantagem de possuir contrafatual claro, pois se compara à distribuição espacial da população entre os municípios, e de possuir significado para o valor zero, que indica ausência de concentração de votos em relação à população. Por outro lado, a interpretação de valores intermediários, como 0,3 ou 0,5, e a comparação com os resultados obtidos entre os diferentes estados não são automáticas e demandam confrontações com outros trabalhos. Ademais, o indicador $G$ não permite que se observe a distribuição dos votos ao longo dos municípios de um estado. Avelino, Biderman e Silva (2016) e Silva e Davidian (2013) também se inspiram na Economia Regional e utilizam o quociente locacional $(Q L)$ como forma de apresentar os mapas de dispersão de votos pelo território, mantendo a mesma lógica de comparação contrafatual que o índice $G$. Apesar dessas considerações, esse indicador nos parece suficiente para a mensuração dos níveis totais de concentração espacial de votos.

Em uma eleição no ano $t$, o nível de concentração tenderá a variar para cada indivíduo $i$ de acordo com o cargo a que concorre: para deputado federal ou para deputado estadual, em cada distrito (e). Além disso, há outros fatores que precisam ser controlados para lidar com a concentração de votos. Desses fatores, uma parte é observável, como o número de candidatos total em disputa $\left(N_{t}\right)$ para determinado cargo em um distrito e o número de candidatos dentro da mesma lista $\left(N_{l}\right)$ para o mesmo cargo - ambos os números são relevantes em relação à capacidade de um candidato individualmente conseguir votos em maior ou menor número de localidades, pois afetam diretamente a concorrência pelo voto de um eleitor; o total gasto com a campanha $(F)^{5}$, que terá importância na medida em que permite que o candidato estenda a sua campanha em uma área maior do território e atinja número maior de eleitores; o total de votos recebido $(V)$, já que um número maior de votos deve ser obtido em uma extensão maior do distrito; se o candidato é do partido vencedor na disputa para o governo do estado (dummy $P G_{i e t}$ igual a 1 se o partido do indivíduo é igual ao partido do vencedor para o governo $)^{6}$, influenciando a dispersão de

\footnotetext{
5 Os dados de gastos de campanha são os dados declarados pelos candidatos em suas prestações de contas ao TSE e estão em milhões de Reais corrigidos pelo IGP para dezembro de 2010.

${ }^{6}$ Esse controle poderia ser complementado pela consideração de o candidato participar ou não da coalizão de governo. Apesar de interessante teoricamente, essa consideração empírica não é factível, já que não se conhece a coalizão de governo nos diversos governos estaduais e seria necessária uma avaliação do impacto temporal de permanência de cada partido em um governo para a construção de um indicador de
} 
votos dos candidatos a deputado por um efeito coattail; se o candidato concorreu nas eleições analisadas por partidos diferentes (dummy $P_{i e t}$ igual a 1 se o indivíduo concorreu por partidos diferentes), relevante na medida em que o esforço de campanha de cada partido é distinto e afeta a todos sob aquela legenda; se o indivíduo se elege ou não (dummy $L_{i e t}$ igual a 1 se o indivíduo se elege), fator que é potencialmente resultante de maior dispersão de votos; e se o indivíduo era incumbente ou não (dummy $I_{\text {iet }}$ igual a 1 se o indivíduo é incumbente), aspecto que permitiria o político se tornar conhecido em áreas do estado onde não recebia votos anteriormente. Outra parte dos fatores que afetam a concentração de votos não é observável, como características idiossincráticas dos distritos $\left(\tau_{e}\right)$ e dos indivíduos $\left(\delta_{i}\right)$, que podem interferir no nível de concentração de seus votos ${ }^{7}$. A Tabela 2 resume as variáveis e seus efeitos esperados sobre o nível de concentração de votos de um candidato:

\section{Tabela 2}

Síntese das variáveis consideradas, conceitos associados e impacto sobre o índice de concentração de votos

\begin{tabular}{|c|c|c|}
\hline Variável & Conceito de referência & $\begin{array}{c}\text { Impacto } \\
\text { sobre } \\
\text { concentração } \\
\text { de votos }\end{array}$ \\
\hline Magnitude (M) & $\begin{array}{l}\text { Número de cadeiras em disputa em um distrito. Proxy da } \\
\text { competição eleitoral }\end{array}$ & + \\
\hline Candidatos $\left(\mathrm{N}_{\mathrm{t}}\right)$ & $\begin{array}{l}\text { Número total de candidatos disputando a eleição para o } \\
\text { mesmo cargo }\end{array}$ & + \\
\hline Candidatos $\left(\mathrm{N}_{\mathrm{I}}\right)$ & $\begin{array}{l}\text { Número de candidatos disputando a eleição para o } \\
\text { mesmo cargo por partido }\end{array}$ & + \\
\hline Financiamento (F) & Total declarado como gasto de campanha - R\$ dez/10 & - \\
\hline $\operatorname{Votos}(\mathrm{V})$ & Total de votos recebidos pelo candidato & - \\
\hline Governador (PG) & $\begin{array}{l}\text { Dummy que indica se o candidato é do mesmo partido do } \\
\text { governador eleito no mesmo pleito }\end{array}$ & - \\
\hline Partido $(P)$ & $\begin{array}{l}\text { Dummy que indica se o candidato mudou de partido entre } \\
\text { as eleições }\end{array}$ & ? \\
\hline Eleito (L) & $\begin{array}{l}\text { Dummy que indica se o candidato se elegeu na disputa de } \\
\text { referência }\end{array}$ & - \\
\hline UF & $\begin{array}{l}\text { Dummy que indica se o candidato mudou de unidade da } \\
\text { Federação (distrito) entre as eleições }\end{array}$ & ? \\
\hline Incumbente (I) & Dummy que indica se o candidato buscava a reeleição & - \\
\hline
\end{tabular}

Fonte: Elaboração do autor.

pertencimento à coalizão. Por exemplo, Borges, Paula e Silva (2016) tentam contornar o problema com um proxy: "a filiação do candidato ao partido do governador em exercício no ano eleitoral" (p. 42), mas isso não seria suficiente para resolver o problema que se desejaria medir com essa variável: o acesso a recursos públicos. No caso deste artigo, a não inclusão da variável medida dessa forma não adiciona nenhum tipo de viés, já que a quantidade de indivíduos em cada um dos grupos de tratamento e controle tende a ser semelhante.

7 Para que um quase experimento possa ser realizado, as variáveis utilizadas como controle precisam estar balanceadas entre os grupos avaliados. No Anexo deste artigo são apresentados os dados mostrando que o balanceamento ocorre para todas as variáveis de controle utilizadas nesta pesquisa.

${ }^{8} \mathrm{O}$ impacto aqui é indicado pelo sinal da variação do índice $G$ : sinais positivos indicam concentração; sinais negativos indicam desconcentração. 
Diante dessas considerações, pode-se dizer que o nível de concentração observado para qualquer um dos cargos respeita a seguinte função ${ }^{9}$ :

$$
G_{i e t}=f\left(N_{e t}, F_{i e t}, V_{i e t}, P_{i e t}, L_{i e t}, I_{i e t}, M_{e}, \delta_{i}, \tau_{e}\right)
$$

Teoricamente, como a magnitude no estado e $\left(M_{e}\right)$ para deputado federal (com $d f$ como notação para esse cargo) é menor do que para deputado estadual (com de como notação para o cargo), a concentração de votos tende também a ser menor. Assim, é possível estabelecer a seguinte relação teoricamente esperada:

$$
G_{i e t}^{d f}<G_{i e t}^{d e}, \forall i, e, t
$$

Há, entretanto, como já dito, um problema empírico com essa comparação direta: ela não é factível, já que nem os indivíduos são comparáveis em suas características não observáveis, nem o mesmo indivíduo concorre aos dois cargos simultaneamente. Em cada eleição, o político concorre por um dos cargos e a dispersão de seus votos depende de fatores não observáveis. Porém, um mesmo indivíduo pode se recandidatar indefinidamente e pode alternar os cargos a que concorre. E de fato os políticos fazem isso. Essa possibilidade permite a eliminação dos efeitos não observáveis $\left(\delta_{i}\right.$ e $\left.\tau_{e}\right)$, se considerarmos a variação do índice de concentração dos votos entre diferentes eleições para um mesmo indivíduo, conforme é possível notar nas construções a seguir:

$$
\begin{aligned}
& G_{i}^{d f-d f}=\Delta G_{i}^{d f}=G_{i e t}^{d f}-G_{i e t-1}^{d f}=\Delta N+\Delta F+\Delta V+\Delta P+\Delta L+\Delta I \\
& G_{i}^{d e-d e}=\Delta G_{i}^{d e}=G_{i e t}^{d e}-G_{i e t-1}^{d e}=\Delta N+\Delta F+\Delta V+\Delta P+\Delta L+\Delta I \\
& G_{i}^{d f-d e}=G_{i e t}^{d f}-G_{i e t-1}^{d e}=\Delta N+\Delta F+\Delta V+\Delta L+\Delta P+\Delta I+\Delta M \\
& G_{i}^{d e-d f}=G_{i e t}^{d e}-G_{i e t-1}^{d f}=\Delta N+\Delta F+\Delta V+\Delta L+\Delta P+\Delta I+\Delta M
\end{aligned}
$$

Como dito, a variação temporal do índice de concentração de votos para o mesmo indivíduo exclui o efeito dos fatores idiossincráticos individuais e do distrito, que são considerados aqui como idênticos nas disputas para os dois cargos. É importante notar que nas equações (5) e (6), $\Delta M$ é a variação das magnitudes de cada distrito entre o cargo federal e o estadual. Já para as equações (3) e (4), esse termo é igual a zero. Se a análise da forma como se apresenta está correta, teoricamente, espera-se que a relação apresentada a seguir valha:

$$
G_{i}^{d e-d f}>G_{i}^{d f-d f} \cong G_{i}^{d e-d e}>G_{i}^{d f-d e}
$$

Ou seja, a maior variação observada seria aquela em que, tudo o mais constante,

\footnotetext{
9 Para efeitos de simplificação, nas equações a seguir a variável $\mathrm{N}$ se refere tanto ao número total de candidatos como ao número de candidatos por lista partidária.
} 
o político altere a sua posição de disputa do cargo de deputado federal para o de deputado estadual entre duas eleições consecutivas ${ }^{10}$. Nessa situação, o número de cadeiras em disputa teria variado positivamente e esse fator implicaria o aumento da concentração de votos. Ao contrário, no caso dos políticos que concorrem inicialmente ao cargo de deputado estadual e depois ao de deputado federal, é esperado que a concentração de votos diminua e, portanto, a variação temporal seja negativa. É possível, assim, construir um teste para essas relações de forma que os controles sejam incluídos. Será utilizado um modelo de regressão com as variações do índice de concentração quando os políticos alternam o cargo em disputa como variável dependente, incluindo as demais variáveis apresentadas acima como controles. Serão considerados apenas indivíduos que tenham concorrido em eleições consecutivas para ponderar se os efeitos não observáveis são de fato estáveis e, assim, podem ser eliminados no desenho de pesquisa proposto. Dessa forma, serão estimados os parâmetros da equação a seguir:

$$
G_{i}^{d j-d k}=\beta_{0}+\beta_{1} \Delta M+\beta_{2} \Delta F+\beta_{3} \Delta V+\beta_{4} \Delta L+\beta_{5} \Delta P+\beta_{6} \Delta I+\beta_{7} \Delta N
$$

em que $d j$ e $d k$ representam os dois cargos em disputa. A relação estabelecida em (7) implica que $\beta_{1}$ seja positivo e esse é o parâmetro de interesse no teste proposto aqui.

\section{Dados}

Para tornar a compreensão dos dados mais clara, vale apresentar a fórmula do índice $G$. Ela é dada pela seguinte expressão:

$$
G_{i}=\sum_{m}\left(\frac{V_{i m}}{V_{i}}-\frac{V_{m}}{V}\right)^{2}
$$

em que $\mathrm{G}_{\mathrm{i}}$ é o índice medido para o candidato $\mathrm{i} ; V_{\mathrm{im}}$ é a votação obtida pelo candidato i na região $m$; $V_{i}$ é o total de votos do candidato $i ; V_{m}$ é o total de votos da região $m$; e $V$ é o total de votos do estado. O que é importante destacar é que esse indicador tem seu mínimo igual a zero e, quanto maior seu valor, mais concentrados espacialmente estão os votos de determinado candidato. Deve-se notar ainda que a região $m$ pode ser qualquer nível geográfico de interesse que esteja inserido em determinado distrito eleitoral, variando desde a seção eleitoral até regiões administrativas do próprio estado. Assim, a primeira avaliação é a das médias do índice $G$ para as quatro eleições analisadas para cada cargo ${ }^{11}$.

\footnotetext{
10 É importante ressaltar que a opção por eleições consecutivas se dá para considerar idênticos os efeitos idiossincráticos dos indivíduos e dos distritos constantes no tempo.

11 Vale dizer que o índice G calculado aqui considerou apenas votos nominais, excluindo, portanto, votos brancos, nulos e de legenda. Esse procedimento teve o objetivo de avaliar apenas a concentração de votos dos candidatos diretamente, de acordo com o debate teórico sobre o tema. Também deve-se informar que seu valor ao longo de todo o texto é referente ao nível microrregional. A escolha desse nível de agregação se dá pelos resultados apresentados em Avelino, Biderman e Silva (2011), que mostram concentração de votos apenas a partir desse nível geográfico. Entende-se assim que a utilização de níveis mais desagregados,
} 
O Gráfico 1 apresenta os resultados:

Gráfico 1

Médias do índice $G$ ponderado por cargo por eleição

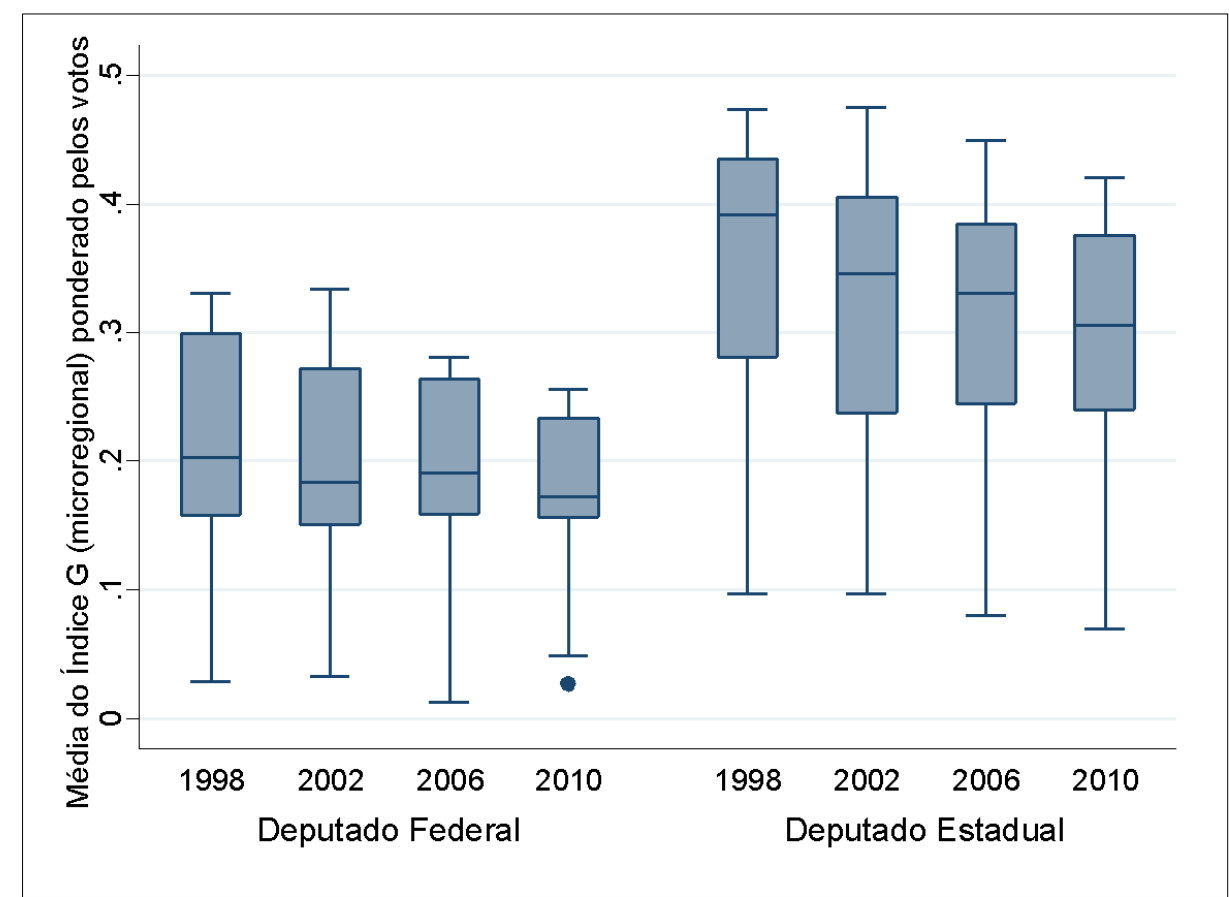

Fonte: Elaborado pelo autor a partir de dados do TSE.

No Gráfico 1, o índice $G$ foi calculado para o nível microrregional, em linha com o encontrado em Avelino, Biderman e Silva (2016). É possível notar que todas as médias, nas quatro eleições, são menores para os candidatos a deputado federal ${ }^{12}$. Já os valores para o cargo de deputado estadual, por apresentarem maior magnitude, são maiores do que os de deputado federal. Isso está de acordo com o esperado: quanto menos cadeiras em disputa, menos concentrados são os votos. É importante destacar que o resultado está relacionado ao número de votos recebido pelo candidato. Ao avaliar as médias do índice $\mathrm{G}$ ponderadas pelo número de votos de cada candidato em cada um dos distritos, nota-se a manutenção do mesmo padrão. A Tabela 3 mostra os valores médios ponderados para cada distrito:

como o municipal, não traria informação adequada ao problema tratado neste artigo.

12 As diferenças entre as médias calculadas para os candidatos a deputado estadual e federal são estatisticamente significantes a $1 \%$. 
Tabela 3

Média do índice $\mathbf{G}$ ponderada por votos por cargo para cada unidade da federação

\begin{tabular}{|l|c|c|c|c|c|c|c|c|c|c|}
\hline & \multicolumn{7}{|c|}{ Deputados federais } & \multicolumn{4}{c|}{ Deputados estaduais } \\
\hline UF & M & 1998 & 2002 & 2006 & 2010 & M & 1998 & 2002 & 2006 & 2010 \\
\hline AC & 8 & 0,20 & 0,20 & 0,15 & 0,09 & 24 & 0,33 & 0,30 & 0,30 & 0,27 \\
\hline AM & 8 & 0,06 & 0,08 & 0,08 & 0,07 & 24 & 0,21 & 0,19 & 0,18 & 0,14 \\
\hline AP & 8 & 0,04 & 0,05 & 0,01 & 0,03 & 24 & 0,10 & 0,10 & 0,08 & 0,07 \\
\hline MS & 8 & 0,20 & 0,19 & 0,16 & 0,16 & 24 & 0,34 & 0,29 & 0,29 & 0,27 \\
\hline MT & 8 & 0,19 & 0,17 & 0,19 & 0,14 & 24 & 0,39 & 0,34 & 0,35 & 0,34 \\
\hline RN & 8 & 0,10 & 0,10 & 0,08 & 0,05 & 24 & 0,20 & 0,22 & 0,19 & 0,19 \\
\hline RO & 8 & 0,26 & 0,33 & 0,28 & 0,23 & 24 & 0,47 & 0,47 & 0,45 & 0,39 \\
\hline RR & 8 & 0,03 & 0,03 & 0,04 & 0,05 & 24 & 0,12 & 0,10 & 0,08 & 0,07 \\
\hline SE & 8 & 0,13 & 0,12 & 0,09 & 0,08 & 25 & 0,28 & 0,24 & 0,19 & 0,17 \\
\hline TO & 8 & 0,15 & 0,17 & 0,21 & 0,14 & 24 & 0,40 & 0,38 & 0,36 & 0,31 \\
\hline AL & 9 & 0,11 & 0,10 & 0,11 & 0,12 & 27 & 0,21 & 0,20 & 0,17 & 0,19 \\
\hline ES & 10 & 0,22 & 0,22 & 0,22 & 0,21 & 30 & 0,43 & 0,38 & 0,38 & 0,38 \\
\hline PI & 10 & 0,11 & 0,11 & 0,07 & 0,09 & 30 & 0,29 & 0,24 & 0,20 & 0,17 \\
\hline PB & 12 & 0,14 & 0,14 & 0,10 & 0,12 & 36 & 0,33 & 0,29 & 0,28 & 0,27 \\
\hline SC & 16 & 0,33 & 0,31 & 0,26 & 0,23 & 40 & 0,47 & 0,46 & 0,45 & 0,42 \\
\hline GO & 17 & 0,16 & 0,13 & 0,16 & 0,12 & 41 & 0,41 & 0,41 & 0,38 & 0,37 \\
\hline PA & 17 & 0,20 & 0,14 & 0,16 & 0,15 & 41 & 0,40 & 0,35 & 0,33 & 0,32 \\
\hline MA & 18 & 0,15 & 0,18 & 0,16 & 0,17 & 42 & 0,40 & 0,34 & 0,30 & 0,27 \\
\hline CE & 22 & 0,14 & 0,13 & 0,12 & 0,13 & 46 & 0,33 & 0,31 & 0,26 & 0,22 \\
\hline PE & 25 & 0,16 & 0,15 & 0,15 & 0,13 & 49 & 0,36 & 0,32 & 0,33 & 0,30 \\
\hline PR & 30 & 0,32 & 0,29 & 0,26 & 0,23 & 54 & 0,45 & 0,40 & 0,42 & 0,40 \\
\hline RS & 31 & 0,28 & 0,23 & 0,22 & 0,19 & 55 & 0,39 & 0,38 & 0,35 & 0,36 \\
\hline BA & 39 & 0,19 & 0,16 & 0,16 & 0,16 & 63 & 0,36 & 0,35 & 0,33 & 0,30 \\
\hline RJ & 46 & 0,16 & 0,15 & 0,18 & 0,17 & 70 & 0,24 & 0,23 & 0,24 & 0,24 \\
\hline MG & 53 & 0,27 & 0,27 & 0,26 & 0,23 & 77 & 0,43 & 0,39 & 0,37 & 0,36 \\
\hline SP & 70 & 0,30 & 0,27 & 0,27 & 0,26 & 94 & 0,45 & 0,42 & 0,42 & 0,38 \\
\hline
\end{tabular}

Fonte: Elaborada pelo autor a partir de dados do TSE.

O que se percebe é que, em qualquer corte observado, os votos para os deputados estaduais são mais concentrados do que os votos para os deputados federais. Seja agrupando os dados pela magnitude do distrito, pelo porte do estado ou pelos votos recebidos pelos candidatos, a dispersão dos votos dos candidatos ao legislativo estadual é menor do que a dos candidatos à Câmara federal.

Embora em linha com as expectativas teóricas, essas observações não são 
suficientes para concluirmos o efeito da magnitude dos distritos sobre os níveis de concentração dos candidatos. Isso porque os procedimentos descritivos feitos acima implicitamente assumem que os candidatos em diferentes distritos são comparáveis entre si. Um candidato a deputado federal eleito pelo Rio Grande do Sul seria comparável com um outro candidato a deputado federal não eleito por Goiás. A disputa em um ou em outro estado estaria condicionada às mesmas forças. Essa suposição é bastante forte, não só pela estruturação dos sistemas partidários locais como também pelas características individuais daqueles que decidem candidatar-se em cada uma dessas localidades. Assim, essas dificuldades devem ser contornadas.

Dessa forma, propõem-se aqui os testes implicados nas equações (7) e (8) acima. O primeiro teste a ser feito é o da equação (8), reproduzida novamente a seguir:

(8) $G_{i}^{d j-d k}=\beta_{0}+\beta_{1} \Delta M+\beta_{2} \Delta F+\beta_{3} \Delta V+\beta_{4} \Delta L+\beta_{5} \Delta I+\beta_{6} \Delta N$

A variação da magnitude dos distritos $(\Delta M)$ deve influenciar positivamente a variação observada do índice $G$. No teste, portanto, espera-se que $\beta_{1}>0$. A Tabela 4 considera a variação da concentração eleitoral de todos os candidatos a deputado - federal ou estadual - que concorreram em eleições consecutivas nas eleições analisadas: 
Tabela 4

Regressão da variação do índice G para candidatos a deputado federal e estadual em eleições consecutivas (1998-2010)

\begin{tabular}{|c|c|c|c|c|c|c|}
\hline & (1) & (2) & (3) & $(4)$ & (5) & $(6)$ \\
\hline \multirow{2}{*}{$\begin{array}{l}\text { Var. } \\
\text { magnitude }\end{array}$} & 0,002 & 0,002 & 0,002 & 0,002 & & 0,002 \\
\hline & $(0,000)^{* * *}$ & $(0,000)^{* * *}$ & $(0,000)^{* * *}$ & $(0,000)^{* * *}$ & & $(0,000) * * *$ \\
\hline \multirow{2}{*}{$\begin{array}{l}\text { Var. } \\
\text { candidatos } \\
\text { total }\end{array}$} & & & & & $7,9 e-05$ & $-7,88 e-06$ \\
\hline & & & & & $(0,000) * * *$ & $(0,000)$ \\
\hline \multirow{2}{*}{$\begin{array}{l}\text { Var. } \\
\text { candidatos } \\
\text { lista }\end{array}$} & & 0,0002 & 0,0001 & $9,93 e-06$ & 0,0001 & 0,0001 \\
\hline & & $(0,000)^{*}$ & $(0,000)$ & $(0,000)$ & $(0,000)$ & $(0,000)$ \\
\hline \multirow{2}{*}{ Var. financ. } & & $-0,011$ & $-2,71 \mathrm{e}-04$ & & $-0,002$ & $-0,0002$ \\
\hline & & $(0,004) * *$ & $(0,004)$ & & $(0,004)$ & $(0,004)$ \\
\hline \multirow{2}{*}{ Var. votos } & & $-2,32 \mathrm{e}-07$ & $-2,46 e-07$ & $-1,66 e-07$ & $-2,63 e-07$ & $-2,46 e-07$ \\
\hline & & $(0,000) *$ & $(0,000)^{*}$ & $(0,000) * * *$ & $(0,000) *$ & $(0,000)^{*}$ \\
\hline \multirow{2}{*}{ Governador } & & $-0,006$ & $-0,006$ & $-0,008$ & $-0,006$ & $-0,006$ \\
\hline & & $(0,006)$ & $(0,007)$ & $(0,006)$ & $(0,007)$ & $(0,007)$ \\
\hline \multirow{2}{*}{ Var. partido } & & 0,016 & 0,012 & 0,011 & 0,013 & 0,012 \\
\hline & & $(0,006) * *$ & $(0,005) *$ & $(0,003) * * *$ & $(0,005) * *$ & $(0,005)^{*}$ \\
\hline \multirow{2}{*}{ Var. UF } & & 0,046 & 0,032 & $-0,005$ & 0,030 & 0,032 \\
\hline & & $(0,045)$ & $(0,045)$ & $(0,051)$ & $(0,044)$ & $(0,045)$ \\
\hline \multirow{2}{*}{ Eleito } & & & 0,001 & 0,003 & 0,003 & 0,001 \\
\hline & & & $(0,004)$ & $(0,003)$ & $(0,004)$ & $(0,004)$ \\
\hline \multirow{2}{*}{ Incumbente } & & & $-0,034$ & $-0,041$ & $-0,035$ & $-0,033$ \\
\hline & & & $(0,005)^{* * *}$ & $(0,004)^{* * *}$ & $(0,005)^{* * *}$ & $(0,005)^{* * *}$ \\
\hline \multirow{2}{*}{ Constante } & $-0,019$ & $-0,031$ & $-0,017$ & $-0,012$ & $-0,020$ & $-0,017$ \\
\hline & $(0,003) * * *$ & $(0,004) * * *$ & $(0,004)^{* * *}$ & $(0,003) * * *$ & $(0,004)^{* * *}$ & $(0,004) * * *$ \\
\hline$R^{2}$ & 0,029 & 0,031 & 0,044 & 0,047 & 0,041 & 0,044 \\
\hline$N$ & 11.678 & 5.013 & 5.013 & 11.678 & 5.013 & 5.013 \\
\hline
\end{tabular}

Fonte: Elaborada pelo autor.

$\neq p<0,10 ; * p<0,05$; ** $p<0,01$; *** $p<0,001$. Erros-padrão clusterizados por UF em parênteses.

Os resultados da Tabela 4 confirmam o esperado teoricamente. Mas antes é preciso fazer uma ressalva: a correlação entre a variação da magnitude $(\Delta M)$ e a variação do número de candidatos total $(\Delta N)$ é bastante elevada $(0,84)$, o que provoca elevada multicolinearidade ${ }^{13}$. Assim, no primeiro modelo, avalia-se o impacto exclusivo da variação da magnitude sobre a variação do índice de concentração. Nos segundo, terceiro e quarto modelos, variáveis de controle são introduzidas e, no quinto modelo, considera-se a variação no número de candidatos em lugar da variação de magnitude. Já na última coluna os resultados apresentados são obtidos com ambas as variáveis simultaneamente. 0 resultado para a magnitude tem o sinal esperado e o valor do coeficiente é expressivo: $0,2 \%$ por cadeira em disputa. Isso significa dizer que a variação positiva de uma cadeira entre diferentes disputas faz com que a votação dos candidatos se concentre mais. No caso extremo de São Paulo, em que a variação entre a disputa para deputado federal e a disputa

\footnotetext{
13 Adota-se a proposição de Kellstedt e Whitten (2013), de que a existência de multicolinearidade não é razão para a exclusão da variável da análise, dado que o impacto dessa manutenção se dá sobre os erros-padrão e não sobre o coeficiente.
} 
para deputado eleitoral é de 24 cadeiras, esse incremento na magnitude implica um aumento médio do índice de concentração de 0,05 ponto - equivalente a toda diferença observada na concentração média para os cargos de deputado federal e deputado estadual nas eleições entre 2002 e 2010, mostrada no Gráfico 1. No extremo oposto, em estados com magnitude menor, como Acre e Tocantins, com 8 deputados federais e 24 deputados estaduais, o nível médio de concentração aumenta em 0,03 ponto. Isso significa uma variação em torno de pouco mais de $25 \%$ dos valores médios apresentados para o índice $\mathrm{G}$ para deputado federal nesses estados ${ }^{14}$. Ainda mais interessante é observar que a inclusão de variáveis de controle nos demais modelos não altera o valor do coeficiente. Ele permanece o mesmo. Mesmo a variável de número de candidatos, quando observada isoladamente, possui efeitos sobre a concentração de votos dos candidatos (quarta coluna), mas perde completamente o efeito quando considerada em conjunto com a magnitude. Uma interpretação possível nessa situação é a de que, ainda que a magnitude seja proxy da disputa intrapartidária, ela não é equivalente ao número de competidores. Há outros componentes importantes que não apenas a relação entre candidatos em disputa e número de vagas, o que, evidentemente, precisaria ser mais bem explorado.

Dentre as variáveis de controle trazidas para o teste, merece destaque o fato de que o montante gasto em campanha pelos candidatos não altera a variação da dispersão de seus votos quando se controla para o fator da incumbência. Ter mais recursos entre as eleições não parece ser mais importante do que o fato de já ocupar um cargo eletivo. Há algo à disposição de quem já está no cargo que faz com que seu voto se disperse mais e que não é capturado pelas despesas declaradas pelo candidato. Vale mencionar que é a introdução dessa variável que reduz o número de observações ${ }^{15}$ entre os modelos acima, já que não há dados de gasto de campanha para todos os candidatos considerados aqui ${ }^{16}$. A introdução do controle de efeito fixo do candidato sugere que a incumbência permite que algo se altere e se reflita na dispersão de votos do político, como a sua popularidade ou o apoio eventual que o partido faz em sua campanha. Já o mesmo não vale para o resultado da eleição: os candidatos que conseguem se eleger não obtêm votos mais dispersos do que aqueles que fracassam. Outro resultado teoricamente esperado é o sinal negativo quanto à variação do voto: quanto maior a votação de um candidato, menos concentrada é essa votação. Aproximadamente, 10 mil votos a mais recebidos por um candidato entre duas eleições têm o mesmo impacto sobre a concentração de sua votação que o aumento de uma cadeira em disputa. Outro resultado que merece comentário é o efeito da mudança de partido entre as eleições. A alteração de legenda pela qual o candidato concorre provoca concentração nos votos dos candidatos. Evidentemente, não é possível explicar as causas desse resultado, mas não deixa de ser relevante observar esse movimento entre eleições.

\footnotetext{
${ }^{14}$ Agradeço a um parecerista anônimo por fazer esse apontamento.

15 Vale mencionar que o número de candidatos deferidos a deputado federal é de 3.360 em 1998, 4.176, em 2002, 4.936 em 2006 e 4.877 em 2010. Já para deputado estadual, os números são 9.936 em 1998, 11.091 em 2002, 11.442 em 2006 e 11.788 em 2010.

16 Esse mesmo efeito ocorre nas Tabelas 6 e 8 adiante pelas mesmas razões.
} 
A mudança de unidade da federação (UF) pela qual o candidato disputa, fato que ocorre com número reduzido de observações (58), também é um controle que não apresenta significância estatística. Por fim, os políticos que estão vinculados ao partido do governador não observam dispersão de votos distinta. Não parece haver impacto sobre a concentração de votos dos candidatos nessa situação.

Gráfico 2

Dispersão entre variação da magnitude e variação do índice de concentração

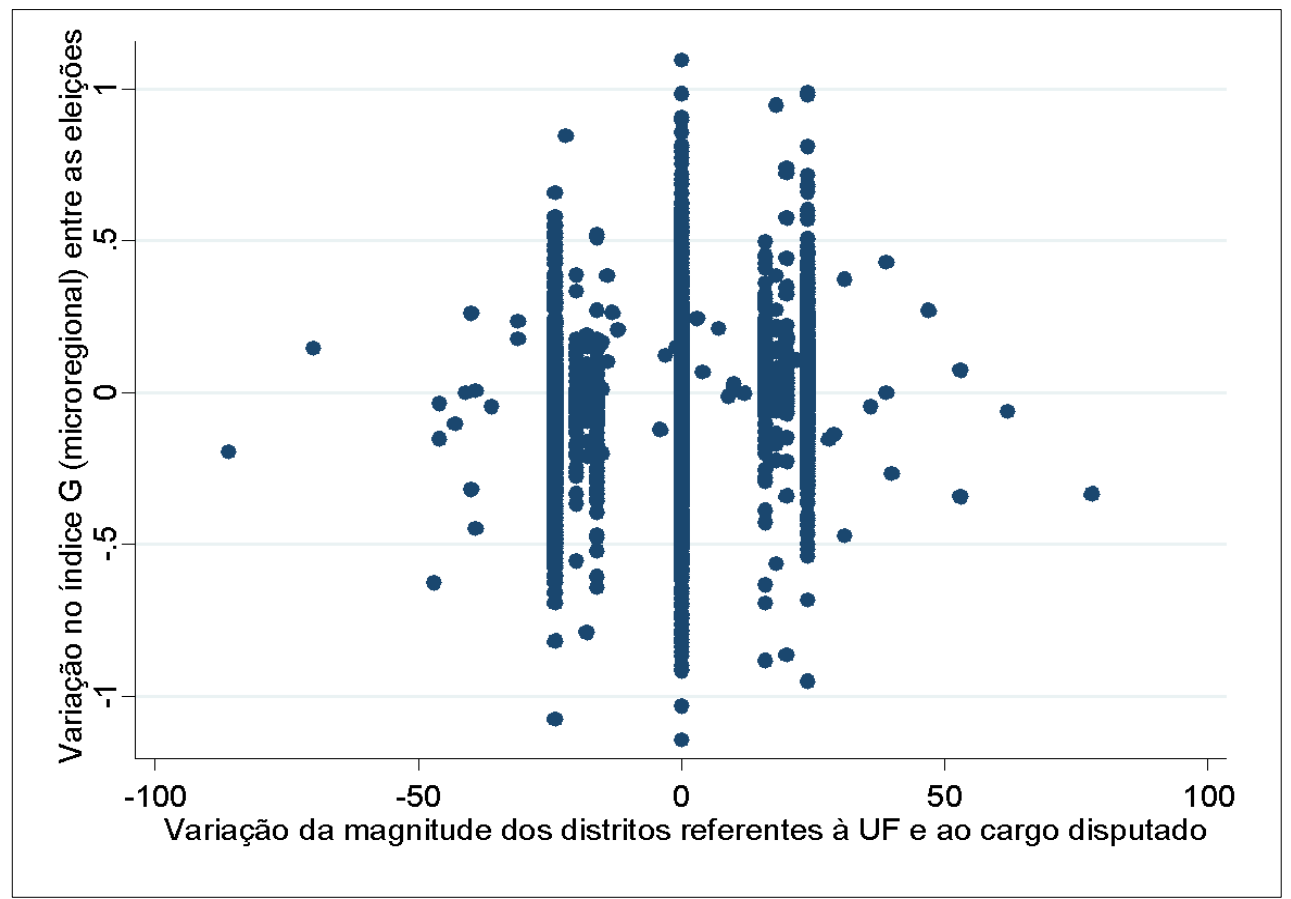

Fonte: Elaborado pelo autor a partir de dados do TSE.

Deve-se ressaltar que os modelos apresentados acima possuem uma medida de ajuste muito baixa - o $\mathrm{R}^{2}$ oscila em torno de 2,9\% a 4,7\%. Apesar disso, é preciso ter em vista que o artigo não se propõe a determinar fatores explicativos para os níveis de concentração de votos dos candidatos, mas, sim, identificar se há relação entre magnitude e concentração regional de votos. Esse é um problema teórico posto pela literatura, mas que ainda não havia sido explorado devidamente. O Gráfico 2 mostra, inclusive, a baixa correlação existente entre a variação da magnitude dos distritos pelos quais os candidatos concorreram e a variação de seus indicadores de concentração regional de votos. Novamente, essa situação não é problemática diante da relação teórica estabelecida para a avaliação do caso brasileiro.

Resta ainda uma avaliação a ser realizada: a comparação das variações dos índices $G$ entre os candidatos aos diferentes cargos como apresentado na equação (7). O primeiro 
passo a ser feito, mais descritivo, é comparar diretamente as médias para cada uma das quatro variações possíveis entre as eleições. A Tabela 5 apresenta estes resultados:

Tabela 5

Médias das variações do índice $\mathbf{G}$ entre os diferentes cargos

\begin{tabular}{|l|c|c|c|c|}
\hline Cargo em t-1 & Cargo em t & Média & Desvio-padrão & N \\
\hline Dep. federal & Dep. estadual & 0,053 & 0,182 & 1.079 \\
\hline Dep. federal & Dep. federal & $-0,012$ & 0,130 & 2.665 \\
\hline Dep. estadual & Dep. estadual & $-0,027$ & 0,145 & 6.676 \\
\hline Dep. estadual & Dep. federal & $-0,066$ & 0,167 & 1.258 \\
\hline
\end{tabular}

Fonte: Elaborada pelo autor.

Apesar de não haver nenhum controle, as variações médias de cada um dos grupos respeitam quase todas as relações esperadas teoricamente. Todas as médias apresentadas na Tabela 5 são estatisticamente significantes a $0,1 \%$. E, de fato, os candidatos que concorrem inicialmente para deputado federal e no pleito seguinte disputam uma vaga no legislativo estadual apresentam a maior variação nos índices de concentração $(+0,053)$ e é a única positiva em todos os grupos. De outra parte, os candidatos que fazem o caminho inverso - disputam primeiro uma eleição para deputado estadual e depois para deputado federal - apresentam o maior grau de desconcentração do índice $G(-0,066)$. A única violação quanto ao previsto pela equação (7) é o fato de que a variação média dos índices de concentração para os políticos que se recandidatam para os mesmos cargos é também diferente para cargos distintos: candidatos a deputado estadual apresentam maior desconcentração do que candidatos a deputado federal. Esse resultado inesperado pode decorrer de uma ação deliberada dos deputados, que se aproveitam do cargo para expandir seu eleitorado, ou como um efeito mecânico do cargo, que aumenta a visibilidade dos eleitos, ainda que não haja uma ação intencional nesse sentido.

Mas, como dito, não há controles nesse modelo e, assim, é preciso incluí-los. Para isso, volta-se ao mesmo modelo de regressão trazido anteriormente e nele é incluída a variação de cargo. São criadas duas variáveis para isso: uma é a dummy para a variação progressiva na carreira, caso dos candidatos que concorrem inicialmente para o cargo de deputado estadual e depois deputado federal; a outra é uma dummy para a variação regressiva na carreira, quando o candidato concorre primeiro para deputado federal e depois para deputado estadual. A Tabela 6 apresenta os resultados obtidos: 
Tabela 6

Resultado da regressão para o índice $\mathbf{G}$ avaliando a variação de cargo

\begin{tabular}{|c|c|c|c|}
\hline & (1) & (2) & (3) \\
\hline \multirow{2}{*}{ Var. progressiva } & $-0,044$ & $-0,022$ & $-0,026$ \\
\hline & $(0,007) * * *$ & $(0,006)^{* * *}$ & $(0,006)^{* * *}$ \\
\hline \multirow{2}{*}{ Var. regressiva } & 0,076 & 0,070 & 0,057 \\
\hline & $(0.008)^{* * *}$ & $(0.008) * * *$ & $(0.008) * * *$ \\
\hline \multirow{2}{*}{ Var. financiamento } & & $-0,010$ & $-0,001$ \\
\hline & & $(0,004) * *$ & $(0,004)$ \\
\hline \multirow{2}{*}{ Variação voto } & & $-2,43 e-07$ & $-2,55 e-07$ \\
\hline & & $(0,000)^{*}$ & $(0,000) *$ \\
\hline \multirow{2}{*}{ Governador } & & $-0,006$ & $-0,006$ \\
\hline & & $(0,006)$ & $(0,007)$ \\
\hline \multirow{2}{*}{ Variação partido } & & 0,015 & 0,012 \\
\hline & & $(0,004) * *$ & $(0,005)^{*}$ \\
\hline \multirow{2}{*}{ Variação UF } & & 0,004 & $-0,004$ \\
\hline & & $(0,040)$ & $(0,040)$ \\
\hline \multirow{2}{*}{ Eleito } & & & 0,002 \\
\hline & & & $(0,004)$ \\
\hline \multirow{2}{*}{ Incumbente } & & & $-0,031$ \\
\hline & & & $(0,005)^{* * *}$ \\
\hline \multirow{2}{*}{ Constante } & $-0,019$ & $-0,035$ & $-0,021$ \\
\hline & $(0,003) * * *$ & $(0,004) * * *$ & $(0,004) * * *$ \\
\hline$R^{2}$ & 0,030 & 0,036 & 0,046 \\
\hline$N$ & 11.678 & 5.013 & 5.013 \\
\hline
\end{tabular}

Fonte: Elaborada pelo autor a partir de dados do TSE.

$\neq p<0,10 ; * p<0,05$; ** $p<0,01$; *** $p<0,001$. Erros-padrão clusterizados por UF em parênteses.

Os resultados para a variação de cargo seguem os mesmos sinais encontrados na Tabela 4, em que não há controles, e correspondem em magnitude também às estimativas feitas no modelo anterior. O sinal do coeficiente varia de acordo com a ambição do político. Quando a carreira do candidato é progressiva - passando da disputa de deputado estadual para federal - o impacto é negativo na variação do índice G. Portanto, seus votos se desconcentram. Porém, quando o candidato passa da disputa como deputado federal para a disputa como deputado estadual, ambição regressiva, seus votos se concentram. Vale mencionar ainda que os sinais e a significância estatística das demais variáveis se mantêm exatamente como nos modelos anteriores, inclusive com relação aos gastos declarados de campanha. É também interessante notar que a constante é significativa em todos os modelos. Na primeira equação, sua interpretação é a mais simples: refere-se aos candidatos que permaneceram na disputa para o mesmo cargo entre as eleições. Novamente, o resultado indica que os votos desses candidatos se dispersam.

A fim de testar a robustez dos resultados obtidos até aqui, é possível restringir a amostra a casos especiais. Um caso de interesse seria observar o comportamento dos candidatos a deputado estadual que obtiveram um número de votos relevante em determinada eleição, mas que no pleito seguinte optaram por trajetórias diferentes. Parte- 
se do princípio de que o candidato a deputado estadual em uma eleição na qual tenha obtido uma votação significativa tenha a possibilidade de, no pleito seguinte, concorrer para o cargo de deputado federal ou estadual com reais chances em ambas as disputas. A competitividade deles seria semelhante do ponto de vista eleitoral, assumindo que a votação em um pleito é um indicativo dessa competitividade, e a comparação entre indivíduos desse grupo se tornaria ainda mais informativa. A restrição a ser utilizada nessa direção é criar o grupo pelo número de votos obtidos e, a fim de tornar o critério comparável entre eleições e diferentes distritos, o procedimento é avaliar a votação obtida em termos de quocientes eleitorais. Seriam comparadas as votações dos candidatos a deputado estadual com o quociente eleitoral da disputa para deputado federal. Dessa forma, a competitividade dos indivíduos estaria controlada, sob a ótica do número de votos obtidos. Repete-se, a partir desse grupo, a análise realizada com as tabelas anteriores.

Apesar de interessante, esse procedimento gera problemas com o número de observações: apenas 108 candidatos a deputado estadual que se recandidataram na eleição seguinte obtiveram ao menos $40 \%$ dos votos equivalentes ao quociente eleitoral da disputa para deputado federal, e apenas 40 obtiveram $50 \%$ desse montante. Outro critério menos restritivo seria considerar o percentual do quociente eleitoral da disputa para deputado estadual. Nesse caso, os candidatos que se aproximassem de determinado patamar teriam conseguido se eleger praticamente apenas com seus votos ou estariam próximos a isso, o que seria um indicativo de sua competitividade. Considerando esse critério, 40 deputados estaduais que se recandidatam conseguiram alcançar o limite de $90 \%$ do quociente eleitoral, enquanto outros 96 alcançaram $75 \%$ desse quociente. Assim, a fim de utilizar uma abordagem que possua número de observações razoável, dois limites - $40 \%$ do quociente eleitoral para a disputa entre deputados federais e $75 \%$ do quociente eleitoral para a disputa entre deputados estaduais - serão trabalhados com intuito de testar a robustez dos resultados mostrados anteriormente. A Tabela 7 apresenta a primeira comparação:

Tabela 7

Médias das variações do índice G para amostra selecionada

\begin{tabular}{|l|c|c|c|c|c|}
\hline Regra & Cargo em t-1 & Cargo em t & Média & $\begin{array}{c}\text { Desvio- } \\
\text { padrão }\end{array}$ & N \\
\hline \multirow{2}{*}{$\begin{array}{l}40 \% \text { quociente eleitoral } \\
\text { dep. federal }\end{array}$} & \multirow{2}{*}{ Dep. estadual } & Dep. estadual & $-0,006$ & 0,054 & 84 \\
\cline { 3 - 6 } & & Dep. federal & $-0,061$ & 0,134 & 24 \\
\hline $\begin{array}{l}75 \% \text { quociente eleitoral } \\
\text { dep. estadual }\end{array}$ & \multirow{2}{*}{ Dep. estadual } & Dep. estadual & 0,010 & 0,063 & 69 \\
\cline { 3 - 6 } & & Dep. federal & $-0,059$ & 0,153 & 18 \\
\hline
\end{tabular}

Fonte: Elaborada pelo autor a partir de dados do TSE.

Os valores médios observados na variação do índice $G$ por aqueles que se mantêm como candidatos a deputado estadual $(-0,006$ e 0,010) não são estatisticamente diferentes de zero. Tal resultado está mais próximo à previsão original, apresentada na equação (7), 
de que não haveria variação do índice $G$ para candidatos que se mantivessem disputando o mesmo cargo. Já o valor médio observado para os indivíduos que disputam o cargo de deputado federal na segunda eleição de acordo com a primeira regra $(-0,061)$ é estatisticamente um valor negativo a um nível de confiança de $1,8 \%$, enquanto pela segunda regra $(-0,059)$ é estatisticamente um valor negativo para um nível de confiança de 5,9\%. Ou seja, são negativos, mas com menor significância do que o que foi observado na Tabela 6. Além disso, as trajetórias distintas dentro de cada um dos grupos, entendidas como a opção em seguir como deputado estadual ou arriscar a disputa pelo cargo de deputado federal, mostram resultados entre si estatisticamente diferentes a pelo menos $0,3 \%$. Portanto, os efeitos encontrados aqui apresentam uma diferença em relação aos resultados anteriores, todos de acordo com as previsões da equação (7): a manutenção da disputa de um mesmo cargo não influencia o nível de concentração de votos. É preciso, então, avaliar os resultados com a inclusão dos controles, tal como feito anteriormente. Assim, na Tabela 8 são reproduzidos os modelos (1) e (3) da Tabela 6 para cada uma das regras de seleção de observações estipulada.

$\mathrm{Na}$ Tabela 8, os dois primeiros modelos se referem à regra de comparação com os $40 \%$ do quociente eleitoral na disputa para deputado federal e os modelos (3) e (4) se referem à regra de comparação com os $75 \%$ do quociente eleitoral na disputa para deputado estadual. Os dados dessa subamostra referem-se apenas a candidatos que ou se mantiveram na disputa pelo mesmo cargo ou perseguiram progressão em sua carreira. Por isso, foi utilizada agora apenas a variável de variação progressiva. É interessante notar que, ainda que os sinais observados da variação de cargo se mantenham, a significância diminui se comparada com os dados da Tabela $6{ }^{17}$. Porém, o valor do coeficiente apresentado nos modelos das colunas (1) e (3), respectivamente, da Tabela 6 não são estatisticamente diferentes dos valores observados na Tabela 8, considerando os mesmos controles. Interessante, aliás, é notar que agora o parâmetro para a constante não é estatisticamente diferente de zero. Aqui, assim como na Tabela 6, os candidatos que permanecem na disputa pelo mesmo cargo apresentam votação com o mesmo nível de dispersão entre as eleições, confirmando o esperado na equação (7). Os novos dados confirmam as expectativas teóricas, já que para os candidatos a deputado estadual que permanecem nessa disputa, o padrão de dispersão de seus votos se mantém entre as eleições. Tal resultado está em contraposição ao anterior que indicava a dispersão dos votos entre as eleições para candidatos com ambição estática e sugere que o efeito de dispersão é mais forte para os indivíduos que na eleição em t-1 obtiveram votações menores que os thresholds considerados aqui. Esses achados merecem futura avaliação. 17 A variável Incumbente foi omitida em razão de sua homogeneidade em todas as observações dessa
amostra. 
Tabela 8

\section{Resultado da regressão para índice $\mathbf{G}$ avaliando a} variação de cargo para amostra selecionada

\begin{tabular}{|l|c|c|c|c|}
\hline & $\mathbf{( 1 )}$ & $\mathbf{( 2 )}$ & $\mathbf{( 3 )}$ & $\mathbf{( 4 )}$ \\
\hline \multirow{2}{*}{ Variação progressiva } & $-0,069$ & $-0,040$ & $-0,055$ & $-0,050$ \\
\cline { 2 - 5 } & $(0,036) \neq$ & $(0,027)$ & $(0,023) *$ & $(0,021) \neq$ \\
\hline \multirow{2}{*}{ Var. financiamento } & & $-0,021$ & & $-0,014$ \\
\hline \multirow{2}{*}{ Variação voto } & & $(0,019)$ & & $(0,020)$ \\
\hline \multirow{2}{*}{ Governador } & & $-2,40 \mathrm{e}-07$ & & $-2,67 \mathrm{e}-07$ \\
\hline \multirow{2}{*}{ Variação partido } & $(0,000)$ & & $(0,000) \neq$ \\
\hline \multirow{2}{*}{ Eleito } & & $-0,015$ & & $-0,009$ \\
\hline \multirow{2}{*}{ Constante } & $(0,018)$ & & $(0,025)$ \\
\hline$R^{2}$ & & 0,013 & & $-0,012$ \\
\hline$N$ & & $(0,012)$ & & $(0,015)$ \\
\cline { 2 - 5 } & & 0,074 & & 0,039 \\
\hline
\end{tabular}

Fonte: Elaborada pelo autor a partir de dados do TSE.

$\neq p<0,10 ; * p<0,05 ; * * p<0,01 ; * * * p<0,001$. Erros-padrão clusterizados por UF em parênteses.

\section{Considerações finais}

O presente artigo buscou aproveitar uma característica do sistema político brasileiro que favorece a avaliação da influência das regras eleitorais. Ao comparar as eleições para deputado estadual e deputado federal nos mesmos distritos, surgem condições de controlar os efeitos não observáveis tanto dos indivíduos quanto dos distritos que influenciam os graus de concentração de votos dos candidatos.

Os resultados obtidos estão de acordo com o esperado teoricamente. O aumento da magnitude leva à concentração espacial de votos. A competição eleitoral avaliada pela magnitude distrital parece estar correlacionada aos efeitos esperados das variações da competição eleitoral intrapartidária. De outra parte, o aumento no número de votos recebidos reduz a concentração. Os políticos, ao conseguirem elevar o número de votos entre eleições, acabam por dispersar suas votações, algo que não é automático, se se leva em conta uma suposta preocupação dos políticos em manter áreas de controle do eleitorado: conseguiriam atingir eleitores fora do seu core. Seria necessário identificar a intencionalidade de suas ações para gerar esse cenário. Mas esse resultado não se mantém quando a amostra é reduzida para candidatos mais votados de acordo com os thresholds considerados aqui. Vale notar que essa é uma evidência produzida por este artigo, em linha com o discutido em Mesquita et al. (2014, p. 89), porém, sem que se tenha uma construção teórica clara para tal resultado. Ainda assim, a expectativa evidenciada pela equação (7) parece valer para candidatos que receberam votação expressiva na eleição em t-1. Essa observação merece maiores investigações, já que remete a algum processo 
de desconcentração de votos que ocorre notadamente para candidatos com menor votação no primeiro pleito. Já a incumbência tem efeito de dispersar os votos entre eleições e acaba por capturar todo o efeito da variação dos gastos declarados de campanha sobre a dispersão de votos dos candidatos. Além disso, o fato de o candidato vencer as eleições não é fator suficiente para que seus votos se dispersem mais que os dos demais candidatos, assim como não é importante estar no mesmo partido do candidato vencedor ao governo do estado para que os votos se dispersem mais. Esses efeitos são importantes por confirmar os sentidos teóricos gerais esperados.

Deve-se enfatizar que os procedimentos acima destacados buscam observar de maneira mais precisa os efeitos da competição eleitoral sobre a concentração regional de votos. O desenho adotado tem limitações quanto às relações causais encontradas em razão do processo de autosseleção envolvido na opção dos candidatos em concorrer por um ou por outro pleito e da consideração que o intervalo entre eleições é suficiente para que se eliminem quaisquer variações de características dos indivíduos. Mesmo assim, o desenho de pesquisa utilizado para este artigo implementa controles precisos para a identificação das relações entre magnitude e concentração de votos, o que não havia sido feito até então, e pode-se, assim, falar em causalidade na relação entre competição e concentração de votos. Ainda, mesmo com os baixos indicadores de ajuste reportados, os resultados trazidos sugerem que a construção teórica possui confirmação empírica, mas novos desenhos precisam ser desenvolvidos.

Por fim, a comparação entre cargos para níveis diferentes sob mesma legislação abre espaço para que outros questionamentos teóricos importantes sejam abordados. Por exemplo, é preciso se perguntar qual a diferença na disputa entre esses cargos para o legislativo em um mesmo estado. Embora estejam sob as mesmas regras e, portanto, teoricamente levariam a resultados semelhantes, as atuações dos candidatos aos cargos podem estar sujeitas a dinâmicas distintas ainda não previstas pela teoria. Por exemplo, as conhecidas "dobradinhas" que relacionam candidatos a deputado federal e estadual em um mesmo distrito durante a campanha podem influenciar a distribuição de votos de ambos. A simultaneidade dessas eleições, somada às eleições majoritárias para o governo nacional e dos estados merece consideração também. Soma-se a isso a atuação dos prefeitos como brokers (Avelino, Biderman e Barone, 2012), o que seria uma força relevante ao longo da campanha para os cargos legislativos. Há ainda que considerar a variação tanto nos candidatos que concorrem e se alternam entre os pleitos, afetando as chances de sucesso entre as eleições, como ainda na quantidade de candidatos que decidem por se recandidatar em uma eleição ou outra. Entende-se que essa informação é endógena ao funcionamento do sistema político, já que se supõe que um determinado político consiga antecipar, ainda que precariamente, suas chances de reeleição e não há ainda meios de considerar essa informação em pesquisas como a proposta aqui. Vale reforçar este ponto: se um político pode antecipar que sua votação será de determinado montante, ele opta por lançar-se candidato para deputado federal ou estadual. A partir de 
sua decisão, observa-se sua votação. Os resultados apresentados sugerem que se são capazes de antecipar tal efeito, os políticos o fazem com precisão. Seriam necessárias maiores investigações a respeito desse aspecto, mas os testes finais com as amostras restritas sugerem que o nível de concentração varia para indivíduos com mesmo montante de votos em razão do cargo disputado e não o contrário. Essas constatações todas, mesmo que não levem automaticamente à discussão sobre o papel dos partidos durante a eleição, sugerem remotamente um caráter coletivo, em termos de coordenação das candidaturas ou, ao menos, não individual nas disputas eleitorais que não foi esgotado pelos estudos empíricos até o presente momento. A investigação apresentada aqui merece ser aprofundada por novas pesquisas.

Glauco Peres da Silva - Universidade de São Paulo. E-mail: <glauco.p.silva@gmail.com>.

\section{Referências bibliográficas}

AMES, B. "Electoral strategy under open-list proportional representation". American Journal of Political Science, vol. 39, no 2, p. 406-433, 1995a.

. "Electoral rules, constituency pressures, and pork barrel: bases of voting in Brazilian Congress". The Journal of Politics, vol. 57, no 2, p. 324-343, 1995b.

The deadlock of democracy in Brazil. University of Michigan Press, p. 352, 2001.

Ames, B.; Pereira, C.; Rennó, L. Famintos por pork. Uma análise da demanda e da oferta por políticas localistas e suas implicações para a representação política. In: PoWER, T.; ZUCCo JR., C. (orgs.). O Congresso por ele mesmo. Autopercepções da classe política brasileira. Belo Horizonte: Ed. UFMG, 2011.

ANDRÉ, A.; DepauW, S. "District magnitude and the personal vote". Electoral Studies, vol. 35, p. 102$114,2013$.

Avelino, G.; Biderman, C.; Silva, G. P. "A concentração eleitoral nas eleições paulistas: medidas e aplicações". Dados, vol. 54, no 2, p. 319-347, 2011.

2016.

"A concentração eleitoral no Brasil (1994-2014)". Dados, vol. 59, no 4, p. 1091-1125,

Avelino, G.; Biderman, C.; BARONE, L. "Articulações intrapartidárias e desempenho eleitoral no Brasil". Dados, vol. 55, 4, p. 987-1.013, 2012.

BAIÃo, A. L. "Emendas orçamentárias individuais: efeitos eleitorais, condicionantes da execução e qualidade do gasto público". Tese de Doutorado em Administração Pública e Governo. Fundação Getúlio Vargas, São Paulo, 2016. 
BLAIS, A.; LAGO, I. "A general measure of district competitiveness". Electoral Studies, vol. 28, p. 94$100,2009$.

Borges, A.; PaUlA, C.; Silva, A. N. "Eleições legislativas e geografia do voto em contexto de preponderância do Executivo". Revista de Sociologia e Política, Curitiba, vol. 24, no 58, p. 31-58, 2016.

CAREY, J.; SHUGART, M. "Incentives to cultivate a personal vote: a rank ordering of electoral formulas". Electoral Studies, vol. 14, no 4, p. 417-439, 1995.

CARROLL, R.; EICHORST, J. "The role of party: the legislative consequences of partisan electoral competition". Legislative Studies Quarterly, vol. 38, no 1, p. 83-109, 2013.

CARVAlHo, N. R. E no início eram as bases: geografia política do voto e comportamento legislativo no Brasil. Rio de Janeiro: Revan, 2003.

CRISP, B.; INGALL, R. "Institutional engineering and the nature of representation: mapping the effects of electoral reform in Colombia". American Journal of Political Science, vol. 46, no 4, p. 733-748, 2002.

CRISP, B., et al. "Vote-earning strategies in flexible list systems: seats at the price of unity". Electoral Studies, vol. 32, no 4, p. 658-669, 2013.

Downs, A. "An economic theory of political action in a democracy". Journal of Political Economy, vol. $65, n^{\circ} 2$, p. 135-150, 1957.

DUVERGER, M. Political parties: their organization and activity in the modern State. York: Methuen, 1959.

Ferree, K.; Powell G. B.; SCheiner, E. "Context, electoral rules and party systems". Annual Review of Political Science, vol. 17, p. 421-439, 2014.

Golden, M.; Min, B. "Distributive politics around the world". Annual Review of Political Science, vol. 16, p. 73-99, 2013.

HAGOPIAN, F. Parties and voters in emerging democracies. In: BOIX, C.; STOKES, S. (eds.). Comparative politics. Oxford Handbooks of Political Science. Oxford: Oxford University Press, p. 582603,2007

KeLLSTEDT, P.; WhITTEN, G. The fundamentals of political research. $2^{\mathrm{a}}$ ed. New York: Cambridge University Press, 2013.

LAGO, I.; RotTA, E. "Conexão eleitoral e reeleição entre deputados federais do sul do Brasil / 19982010". Revista de Sociologia e Política, vol. 22, no 49, p. 139-156, 2014.

MARTIN, S. "Using parliamentary questions to measure constituency focus: an application to the Irish case". Political Studies, vol. 59, no 1, p. 472-488, 2011.

MAYHEW, D. R. Congress: the electoral connection. New Haven: Yale University Press, 1974.

MESQUITA, L., et al. "Emendas individuais e concentração de votos: uma análise exploratória". Teoria \& Pesquisa, vol. 23, n² 2, p. 165-178, 2014. 
NEMOTO, K.; SHUGART, M. "Localism and coordination under three different electoral systems: the national district of the Japanese House of Councillors". Electoral Studies, vol. 32, no 1, p. $1-12$, 2013.

Pereira, C.; RenNó, L. "O que é que o reeleito tem? Dinâmicas político-institucionais locais e nacionais nas eleições de 1998 para a Câmara dos Deputados". Dados, vol. 44, no 2, p. 323-362, 2001.

. "O que é que o reeleito tem? O retorno: o esboço de uma teoria da reeleição no Brasil". Revista de Economia Política, vol. 27, no 4, p. 664-683, 2007.

PRIMO, D.; SNYDER Jr., J. "Party strength, the personal vote, and the government spending". American Journal of Political Science, vol. 54, n 2, p. 354-370, 2008.

RAE, D. Political consequences of electoral laws. New Haven: Yale University Press, 1972.

SiLVA, G. P. "Uma avaliação empírica da competição eleitoral para a Câmara Federal no Brasil". Opinião Pública, vol. 19, nº 2, p. 403-429, 2013.

Silva, G. P.; Davidian, A. "Identification of areas of vote concentration: evidences from Brazil". Brazilian Political Science Review, São Paulo, vol. 7, nº 2, p. 141-155, 2013.

StAdelmann, D., PORTMAnN, M.; Eichenberger, R. "The law of large districts: how district magnitude affects the quality of political representation". European Journal of Political Economy, vol. 35, p. 128-140, 2014.

Swindle, S. "The supply and demand of the personal vote", Party Politics, vol. 8, no 3, pp. 279-300, 2002.

VignANDI, R. S.; PARRÉ, J. L.; GUimaRÃES, P. F. "Concentração industrial no Brasil: uma análise espacialmente ponderada". In: Anais do XLI Encontro Nacional de Economia. Anpec - Associação Nacional dos Centros de Pós-Graduação em Economia, 2014. 
Anexo

\section{Comparação das variáveis de controle para os grupos de candidatos}

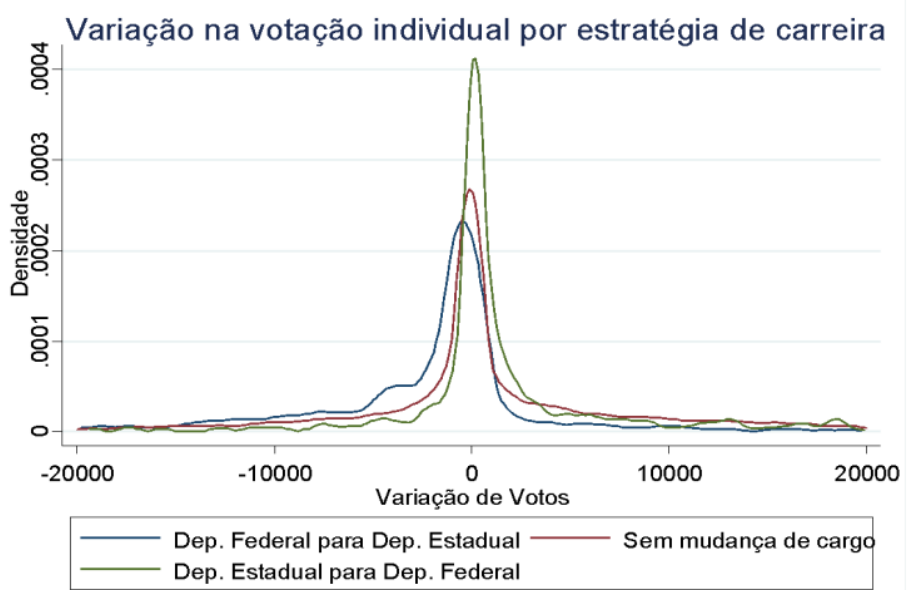

Variação do Financiamento de Campanha por estratégia de carreira

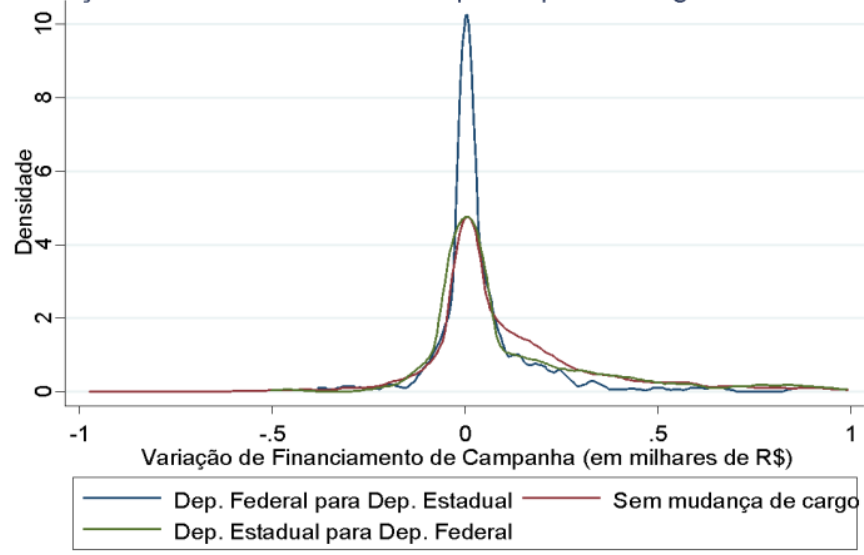


MESMAS INSTITUIÇÕES, MESMOS RESULTADOS?
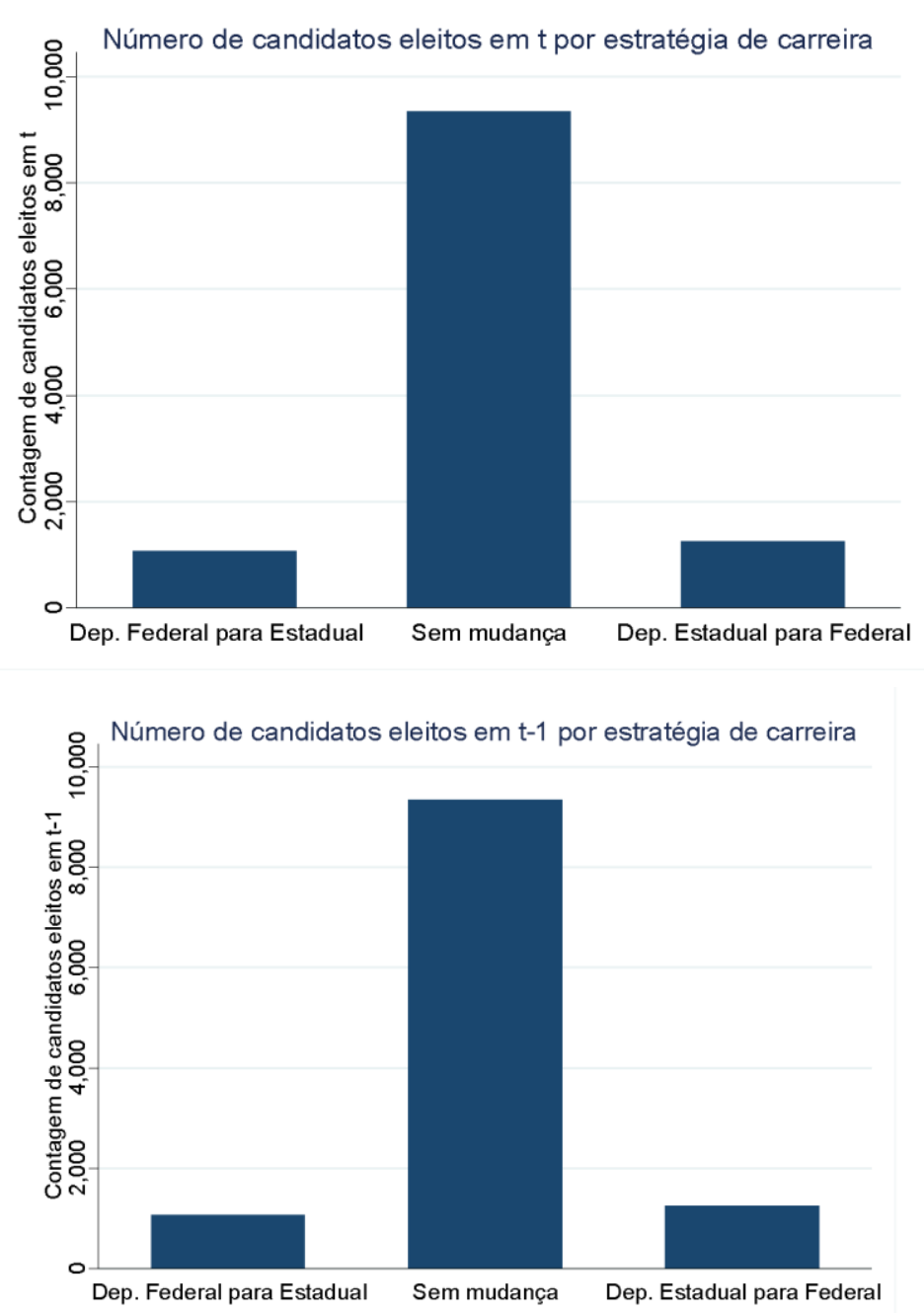

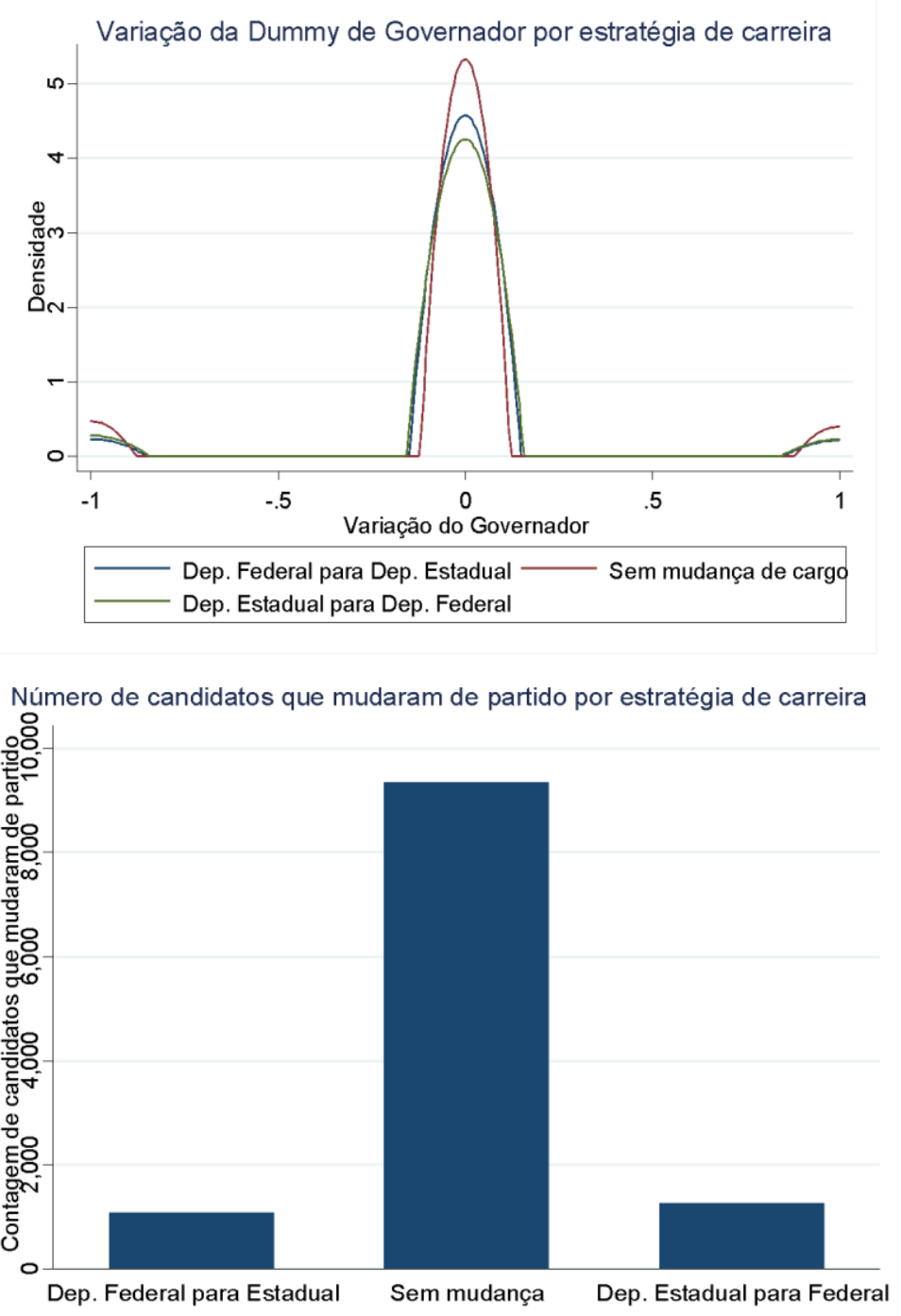


\section{Resumo}

Mesmas instituições, mesmos resultados? Comparando o efeito da competição eleitoral sobre os níveis de concentração de votos

O objetivo do artigo é identificar o efeito da magnitude dos distritos eleitorais sobre a concentração espacial de votos. Usualmente, a magnitude dos distritos é proxy para o nível de competição intrapartidária e esta incentivaria o voto pessoal. Nos estudos sobre o Brasil, assim como em outros trabalhos, o voto pessoal justificou a concentração regional de votos. Porém, ainda persiste a dificuldade em identificar essa relação porque, apesar dos distritos possuírem diferentes magnitudes, não se deve confrontar diretamente os níveis de concentração de diferentes candidatos. Entretanto, a simultaneidade das eleições para o legislativo estadual e federal no caso brasileiro cria um caso de quase-experimento, ao se controlar para as alternâncias dos indivíduos em concorrer entre cargos ao longo do tempo. Este artigo cobre o período de 1998 a 2010 e os resultados indicam que variações de magnitude levam a concentração espacial dos votos, confirmando as expectativas teóricas.

Palavras-chave: competição eleitoral; deputado federal; deputado estadual; concentração espacial de votos; magnitude distrital

\section{Abstract}

Same institutions, same outcomes? Comparing the effect of electoral competition on the level of concentration of votes

The purpose of this paper is to identify the effect of electoral district magnitude on the spatial concentration of votes. Usually, district magnitude is a proxy for intraparty electoral competition, which incentivizes the personal vote. Studies about Brazil and other countries have considered the personal vote an explanation for the regional concentration of votes. However, the difficulty in directly identifying the concentration levels still remains-even though the districts possess different magnitudes-because the concentration levels of different candidates must not be directly compared. Nevertheless, the electoral simultaneity of the federal and the state legislative elections offers a quasiexperimental case for the effect of different magnitudes over votes' spatial concentration, controlling for the variation of disputed seats over time. The data ranges from 1998 to 2010 and results indicate the magnitudes lead to the regional concentration of votes, confirming theoretical expectations.

Keywords: electoral competition; federal congressmen; state congressmen; vote spatial concentration; district magnitude

\section{Resumen}

¿Las mismas instituciones, los mismos resultados? Comparando el efecto de la competencia electoral sobre los niveles de concentración de votos

El objetivo de este trabajo es identificar el efecto de la magnitud de los distritos electorales sobre la concentración espacial de votos. Usualmente, la magnitud de los distritos es proxy para el nivel de competencia intrapartidaria y ésta incentivaría el voto personal. En los estudios sobre Brasil, así como en otros trabajos, el voto personal justificó la concentración regional de votos. Sin embargo, todavía persiste la dificultad de identificar esta relación porque, a pesar de que los distritos poseen diferentes magnitudes, no se debe confrontar directamente los niveles de concentración de diferentes candidatos. Sin embargo, la simultaneidad de las elecciones al legislativo estatal y federal en el caso brasileño crea un caso de cuasi-experimento, al controlarse las alternancias de los individuos al competir para cargos a lo largo del tiempo. El artículo cubre el período de 1998 a 2010 y los resultados indican que las variaciones de magnitud llevan la concentración espacial de los votos, confirmando las expectativas teóricas.

Palabras clave: la competencia electoral; diputado; la concentración espacial de los votos; la magnitud de distrito 


\section{Résumé}

Mêmes institutions, mêmes résultats? Comparer l'effet de la compétition électorale sur les niveaux de concentration des votes

L'objectif de ce travail est d'identifier l'effet de l'ampleur des circonscriptions sur la concentration spatiale des votes. Habituellement, l'ampleur des districts est un indicateur du niveau de la concurrence interne du parti, ce qui encouragerait le vote personnel. Dans les études sur le Brésil, comme dans d'autres travaux, le vote personnel justifiait la concentration régionale des voix. Cependant, la difficulté persiste quand il s'agit d'identifier cette relation car, bien que les districts aient des tailles différentes, il ne faut pas confronter directement les niveaux de concentration des différents candidats. Cependant, la simultanéité des élections législatives et fédérales dans le cas brésilien crée un cas de quasi-expérimentation, en contrôlant les alternances des individus dans la compétition entre les positions dans le temps. L'article couvre la période de 1998 à 2010 et les résultats indiquent que les variations de magnitude conduisent à une concentration spatiale des votes, ce qui confirme les attentes théoriques.

Mots-clés: compétition électorale; membre du Congrès; la concentration spatiale des votes; circonscription

Submetido em 14 de novembro de 2016. Versão final aprovada em 2 de outubro de 2017. 